\title{
Preparedness of the Local Community in the Fight Against COVID-19 in Dodoma Urban, Tanzania
}

\author{
Yusuph Lameck Mashala \\ Local Government Training Institute, Dodoma, Tanzania \\ Department of Local Government Administration and Management \\ E-mail: m_lameck@yahoo.com \\ Lazaro Alman Kisumbe \\ Local Government Training Institute, Dodoma, Tanzania, \\ Department of Human Resource Management \\ E-mail: lkisumbe04@yahoo.com \\ Manumbu Hezron Daudi \\ Local Government Training Institute, Dodoma, Tanzania \\ Department of Local Government Administration and Management \\ E-mail: dmanumbu@yahoo.com
}

Received: Jun. 23, 2020 Accepted: Aug. 17, 2020 Online published: Sept. 3, 2020

doi:10.5296/jpag.v10i3.17235 URL: https://doi.org/10.5296/jpag.v10i3.17235

\begin{abstract}
Since its outbreak in late December 2019, COVID-19 has brought a state of fear, panic, insecurity and a high level of uncertainty to the whole population of the world. Amid these uncertainties, governments and international organizations across the world, have adopted various measures against its spread; such measures have depended on the nature and severity of the disease and the suitable approach adopted by each particular country. This study assessed the preparedness of the local community in the fight against COVID-19 in Dodoma Urban, Tanzania. Data were collected through a questionnaire from 100 respondents who were coincidentally selected. We analyzed data through descriptive statics and Binary Logistic Regression. The overall results show that the majority of respondents $(53.68 \%)$ were
\end{abstract}


well prepared to curb COVID-19. Nevertheless about $46 \%$ of the respondents were inadequately prepared. In order to curb the spread of the disease in Dodoma urban, the study recommend that the local community should consistently adhere to government directives, keep informed of the situation, and respond appropriately to protect themselves, their families, and others against the deadly corona virus disease.

Keywords: COVID-19, community preparedness, Dodoma urban, Tanzania

\section{Introduction}

The Corona Virus Disease 2019 (COVID-19) emerged in Wuhan City, Hubei Province; China in December 2019 has spread all over the world. The spread of the disease has so far compelled countries and international organizations to assume the dramatic features of pandemic emergency (Lippi \& Plebani, 2020). There exist different stories regarding the root causes of the eruption of COVID-19 in Wuhan City, the epicenter of the disease. Scholars have perceived that COVID-19 emanated from animals/bats to human beings and person to person (Benvenuto et al., 2020; Purcell \& Charles, 2020; Singhal, 2020). The transmission from person to a person happens through various ways including touching droplets generated by an affected person through sneezing, coughing, and handshaking (Singhal, 2020; Spina et al., $2020 \mathrm{WHO}, 2020)$.

The infected person of COVID-19 demonstrates different symptoms. Moreover, Medical practitioners have demonstrated the common clinical symptoms of the infected person including fever, cough, sore throat, fatigue, headache, and breathlessness (Singhal, 2020). Even though the disease has claimed more than three hundred thousand lives worldwide and detrimentally affected social and economic situations (WHO, 2020; Dosa, Jump, D, \& Gravenstein, 2020), so far there is neither vaccine nor medical treatment for the disease (Korea \& Kong, 2020). Based on its pathological effects on human lives, the World Health Organization (WHO) on January $30^{\text {th }}, 2020$ declared it to be a Public Health Emergency of International Concerns (Purcell \& Charles, 2020; WHO, 2020). Further, Antonio Guterres, the Secretary-General of the United Nations, described COVID-19 as the worst crisis against humanity since the Second World War.

Since its outbreak in late December 2019, the coronavirus disease has brought a state of fear, panic, insecurity and a high level of uncertainty to the whole population of the world. Amid these uncertainties, governments and international organizations across all continents have been struggling to impose different measures to overcome and protect citizens from contracting or spreading the disease. Some common measures including, but not limited to cancellation of international and some domestic flights, school closure, banning public gatherings, self-isolation, quarantine, and work from home (Singhal, 2020; Spina et al., 2020; Williams, 2020). Other measures include rapid identification, rapid diagnosis, contact tracing, social distancing, use of sanitizers, handwashing and wearing masks (Korea \& Kong, 2020; Purcell \& Charles, 2020; Singhal, 2020). These measures have proved effective to contain the pandemic in some countries like China, German, and South Korea (Korea \& Kong, 2020).

However, most of the developing countries including Africa find it difficult to adopt some of 
these measures because of different reasons. The reasons include ill-equipped pharmaceutical equipment for diagnosis, delays in patient isolation, inability to relate confirmed cases through chains of transmission for a large number of cases, and limited knowledge of citizens on the pandemic (Korea \& Kong, 2020; WHO,2020). Even though most African countries are claimed to have tropical pandemic preparedness plans including influenza and Ebola, they appear to inadequately respond to the Corona Virus pandemic (Korea \& Kong, 2020).

Unlike America, Europe, and some of the Asian countries, little efforts have been undertaken to address the spread of the disease in Africa. This is reflected by crowds emanating from commuter buses, religious gatherings, and recreational facilities (Williams, 2020). These scenarios have been advocated by developing countries, international organizations, politicians, and influential individuals that may put Africans at the highest risk of contracting the disease. Therefore, the question of whether Africa will afford to withstand the pandemic as its counterpart in America, Europe, and Asia remains critical.

Moreover, as the intensity of COVID-19 increases worldwide, medical experts warned that it was just a matter of time before, Africa witnesses massive eruption of the diseases and their effects (Vuzo, 2020). The first case of COVID-19 was reported in Egypt on $14^{\text {th }}$ February 2020. Since then, several cases have been reported in different African countries with increasing numbers in capital cities (WHO, 2020). Specifically, Tanzania reported the first case of the disease on $16^{\text {th }}$ March 2020 . The number of cases kept on the increase whereby on $20^{\text {th }}$ April 2020, a total of 87 cases were reported in the country (MoHSW, 2020).

The increased number of cases in Tanzania made the government take decisive measures to mitigate its spread. The initial measures included creating awareness to the community, use of sanitizers, closure of primary, secondary, colleges, and universities, restricting traveling, and 30 days ban on public gatherings including sports and music events, political meetings, and community events. Additionally, the government suspended all international flights. Likewise, the government established COVI-19 patient centers in every region to handle infected cases. Besides, government officials have insisted on the use of traditional medicines as a remedy to the fight against the corona pandemic. Further, the government invited the media houses and religious leaders to take part in the war against the pandemic.

Despite the efforts, it remains unfolded regarding the local community preparedness to counter the spread of the coronavirus in Dodoma Urban. The preparedness implies community adherence to international and national guidelines geared towards addressing the spread and pathological effects of the pandemic. The study, therefore, meant to bridge the knowledge gap and add to the existing literature by assessing the preparedness of the Local Community of Dodoma Urban, Tanzania in the fight against COVID-19.

\section{Materials and Methods}

\subsection{Study Area}

The study was conducted in Dodoma urban as shown in Figure 1. Dodoma urban is the capital city of Tanzania, the home of the Parliament of Tanzania, government ministries and agencies. 


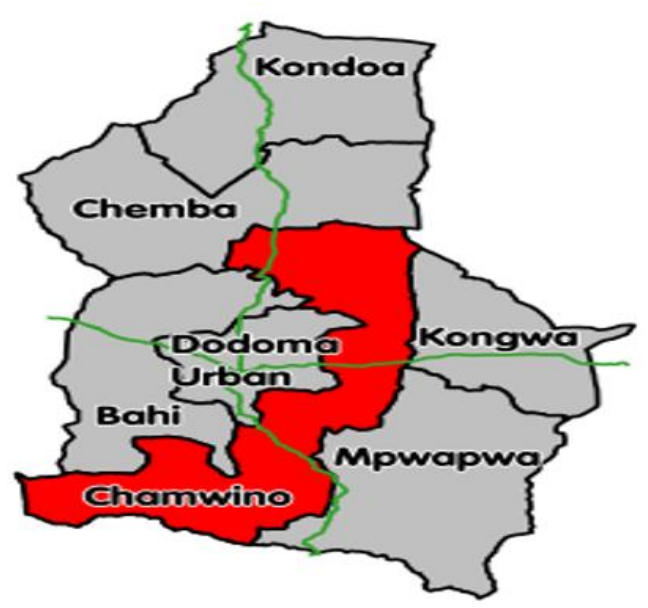

Figure 1. Geographical location of Dodoma Urban

The area was selected since recently it has experienced an increase of social, economic, and political interactions following the government decided to transfer the government business from Dar Es Salaam to Dodoma. As a result, the population of Dodoma urban has increased manifold causing mushrooming of business, transportation, and social activities in the area. This indicates that perhaps the area is more vulnerable to COVID-19.

\subsection{Data Collection and Sample}

The study involved 100 respondents accidentally selected. The selection criteria involved only residents of Dodoma urban who were willing to participate in the study. We collected data through questionnaires written in both English and Kiswahili languages. We administered the questionnaire through a face-to-face for 70 participants and 30 questionnaires were administered through email.

\subsection{Data Analysis}

We analyzed data using Descriptive Statistics and Binary Logistic Analysis. Most of the data were presented in the form of percentages, frequencies, tables, and charts. A logistic regression equation $\log \left(\frac{\mathrm{P}}{1-\mathrm{P}}\right)=\alpha+\beta_{1} \mathrm{X}_{1}+\beta_{2} \mathrm{X}_{2}+\cdots+\beta_{\mathrm{k}} \mathrm{X}_{\mathrm{k}}$ was established. Whereby: $\mathrm{P}=$ Probability of an event to occur. In this study, the probability of a respondent being well prepared, $\alpha=$ is the intercept. The odd when there are no predictors in the model. $\beta_{1}, \beta_{2}, \ldots \beta_{k}$ $=$ are estimated parameters. $\mathrm{x}_{1}, \mathrm{X}_{2} \ldots \mathrm{X}_{\mathrm{k}}=$ are predictors in the model (Independent variables). We employed this model to assess the probability of an event to occur (well preparedness) as influenced by age, sex, and education level compared to moderately prepared level. A poorly prepared level was dropped since only two respondents felt under the category. A response variable had two categories coded ( $\mathrm{Y}=1$ if the event happened (well prepared) and $\mathrm{Y}=0$ if the event not happened (moderately prepared). 


\section{Results}

\subsection{Demographics}

One hundred (100) respondents participated in the study. Among these, ninety-nine (99) participants indicated their age and sex as shown in Table 1.

Table 1. Demographic Characteristics of Respondents

\begin{tabular}{lcc}
\hline \multicolumn{1}{c}{ Variable } & Frequency $(\boldsymbol{n})$ & Percentage $(\boldsymbol{\%})$ \\
\hline Gender of Respondents & 57 & \\
Male & 42 & 58 \\
Female & $\mathbf{9 9}$ & 42 \\
Total & & $\mathbf{1 0 0}$ \\
Age of Respondents & 36 & \\
$18-25$ & 33 & 36.4 \\
$26-33$ & 16 & 33.3 \\
$34-41$ & 8 & 16.1 \\
$42-49$ & 6 & 8.1 \\
50 and Above & $\mathbf{9 9}$ & 6.1 \\
\hline Total & & $\mathbf{1 0 0}$ \\
\hline
\end{tabular}

Results in Table 1 show that $57(57.58 \%)$ were male and $42(42.42 \%)$ were female. This implies there was adequate representation of all sex in the study. Moreover, $36.4 \%$ of respondents were $18-25$ years, $33.3 \%$ were $26-33$ years, $16.1 \%$ were $34-41$ years, $8.1 \%$ were 42-49 years and $6.1 \%$ were 50 years and above. The results show that the majority of respondents were aged 18 to 33 years. This implies that the majority of the participants who were willing to participate in the study belong to the youth group of the population. This is related to the youth being the most active section of the population engaging in various economic activities, which made accessible during the study.

Table 2. Respondents' Education by Sex

\begin{tabular}{ccccc}
\hline \multicolumn{5}{c}{ Respondent's Education by Sex } \\
Sex & $\begin{array}{c}\text { Bachelor } \\
\text { and higher }\end{array}$ & Secondary & STD VII & Total \\
\hline Female & 18 & 13 & 11 & 42 \\
Percent & 18.18 & 13.13 & 11.11 & 42.42 \\
Male & 30 & 14 & 13 & 57 \\
Percent & 30.3 & 14.14 & 13.13 & 57.58 \\
Total & 48 & 27 & 24 & 99 \\
Percent & 48.48 & 27.27 & 24.24 & 100 \\
\hline
\end{tabular}

Source: Survey Data, 2020

Table 2 shows that out of 42 females, 18 (18.18\%) hold a minimum of a bachelor, 13 $(13.13 \%)$ were secondary school levers and $11(11.11 \%)$ were standard seven. Also, 30 $(30.30 \%)$ of the males hold a minimum of a bachelor's degree, $14(14.14 \%)$ were secondary 


\section{Macrothink}

school levers and $13(13.13 \%)$ were standard seven. The results suggest that people with a minimum of bachelor's degrees were more willing to participate in the study.

\subsection{Respondents' Understanding About COVID-19}

The understanding regarding COVID-19 among the respondents is the prerequisite requirement in the attempt to mitigate its spread. A definition provided by (WHO, 2020) that Coronavirus disease (COVID-19) is the illness caused by a novel corona virus commonly referred to as called severe acute respiratory syndrome coronavirus 2 (SARS-CoV-2), was used as a benchmark to test respondents understanding about COVID-19. Each response was assigned a number ranging from 1 to 3 . The total score of each response was calculated and converted into a percentage. The percentage scores were classified into high for responses scored 1; meaning responses similar to the benchmarked definition, Moderate for responses scored 2, meaning the understanding provided was too close to the benchmarked definition, and low for responses scored 3, for completely unrelated meaning. Figure 2 shows the respondents' understanding of COVID-19.

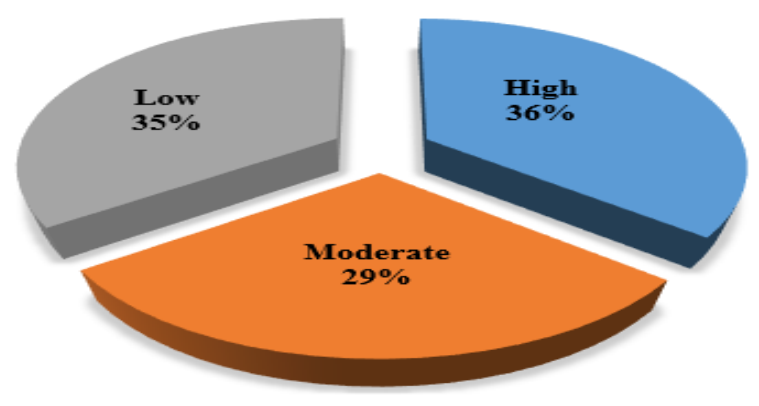

Figure 2. Respondents Understanding About COVID-19

Source: Field Data, 2020

The results show that $36 \%$ of the respondents had a high understanding, $28 \%$ had a moderate understanding and 35\% had a low understanding of COVID-19. These results indicated that the majority of participants had a general understanding of COVID-19. Moreover, the results imply that there is a high chance of the majority of respondents to take precaution against the coronavirus. However, some deliberate efforts have to be done specifically on the respondents with low understanding to enable them to have adequate knowledge of COVID-19. Further, respondents' understanding was measured in terms of education as shown in figure 3. 


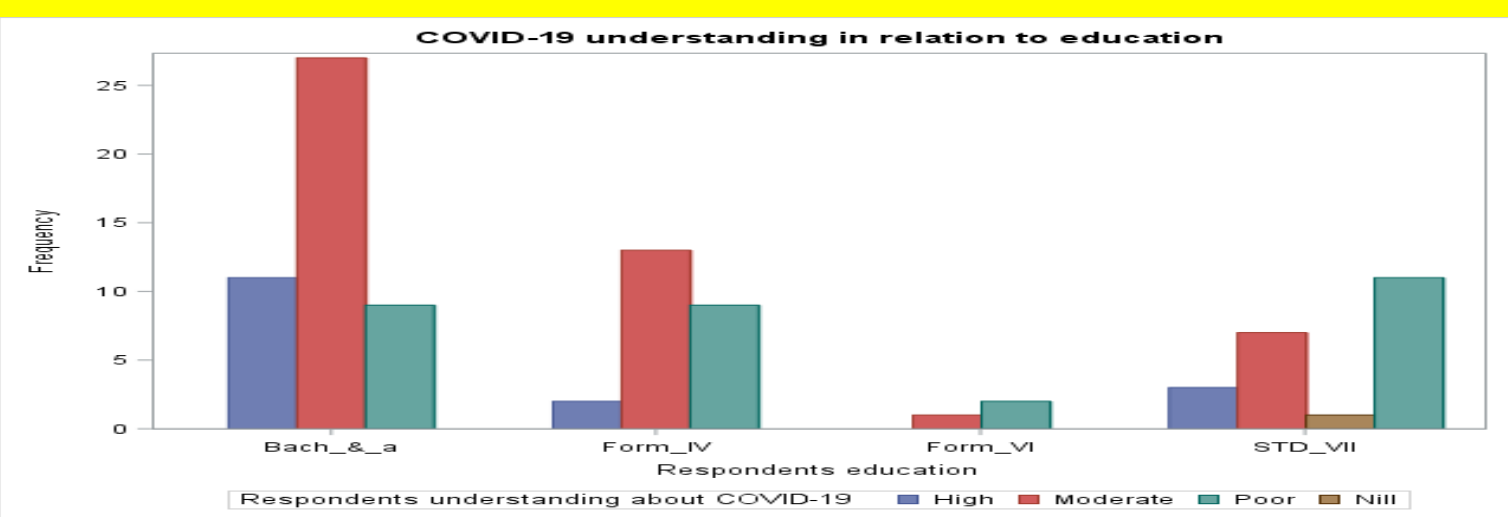

Figure 3. Respondents understanding of COVID-19

Source: Field Data, 2020

The results show that 45 (45\%) respondents had a high understanding, 5 (5\%) had a poor understanding and 48 (49\%) had a moderate understanding regarding COVID-19. Further, $47 \%$ of respondents with a minimum of bachelor degrees had a high understanding of COVID-19 as compared to secondary and standard seven. The findings generally suggest that the respondents have a good understanding of COVID-19.

\subsection{Community Awareness on the Spread of COVID-19}

The respondents' level of awareness regarding the ways through which COVID-19 spreads is a paramount factor in designing a mechanism to mitigate the problem. Thus, the findings from 99 respondents regarding the identified means through which the disease spreads are summarized in Table 3

Table 3. Ways through which COVID-19 spreads

\begin{tabular}{rllcc}
\hline S/N & \multicolumn{1}{c}{ Ways } & f & \% \\
\hline 1. & Handshakes & 39 & 39.4 \\
2. & Direct contact with a COVID-19 patient & 23 & 23.3 \\
3. & $\begin{array}{l}\text { Touching the droplets/fluids from the victim after } \\
\text { sneezing or coughing }\end{array}$ & 42 & 42.4 \\
4. & Through air & & \\
5. & Touching contaminated surfaces & 20 & 20.2 \\
\hline
\end{tabular}

Source: Field Data, 2020

The results in Table 3 show that 39(39.4\%) respondents identified a handshake with the infected person as a contributing factor to the spread of COVID-19. Further, 16(16.2\%) of the respondents' mentioned touching contaminated surfaces as the contributing factor for the spread of the disease. This implies that the majority of participants were aware of how COVID-19 spreads. However, awareness among the respondents differed based on the levels of education. The findings in Table 4 provide for the summary of the extent of the participants' awareness of the pandemic based on their level of education. 
Table 4. The extent to which participants are aware of the spread of COVID-19

\begin{tabular}{lcccc}
\hline & High & Understanding the level & \\
Education Level & 20 & 23 & 4 & Total \\
\hline Bachelor and high & 20.41 & 23.47 & 4.08 & 47.96 \\
Percent & 2 & 18 & 7 & 29 \\
Secondary & 2.04 & 18.37 & 7.5 & 29.55 \\
Percent & 1 & 12 & 11 & 24 \\
Standard Seven & 1.02 & 12.24 & 11.22 & 24.49 \\
Percent & $\mathbf{2 3}$ & $\mathbf{5 3}$ & $\mathbf{2 2}$ & $\mathbf{9 8}$ \\
\hline Total & $\mathbf{2 3 . 4 7}$ & $\mathbf{5 4 . 0 8}$ & $\mathbf{2 2 . 4 5}$ & $\mathbf{1 0 0}$ \\
Percent & & & & \\
\hline
\end{tabular}

Source: Field Data, 2020

Results in Table 4 show that about a quarter (23.47\%) of the respondents with a minimum of Bachelor's Degree revealed a moderate understanding of the coronavirus. Thus, only less than a quarter $(20.41 \%)$ of them revealed a higher understanding of the disease. Similarly, 18 $(18.37 \%)$ of the secondary education holders had a moderate understanding of the disease. Regarding the respondents with primary education level, 12(12.24) depicted moderate understanding. Additionally, regarding poor understanding, respondents with primary education scored higher $(11.22 \%)$ and the respondents with a minimum of bachelor degree revealed the lowest number of respondents with poor understanding. The findings suggest that the higher the level of education, the higher the level of understanding of the coronavirus pandemic.

\subsection{Community Preparedness to Curb COVID-19}

The preparedness of the community to deal with pandemic was assessed by examining the ways used to minimize the chances for its spread. Further, the effects of education level on the respondent's preparedness were examined. The summary of the findings is provided in Tables 5 and 6 respectively.

Table 5.Ways showing Community Preparedness to curb COVID-19

\begin{tabular}{|c|c|c|}
\hline Ways & $\mathbf{f}$ & $\%$ \\
\hline Use of masks and groves & 10 & 6.01 \\
\hline Frequent hand Washing & 53 & 31.9 \\
\hline Use of sanitizers & 21 & 12.7 \\
\hline Avoid highly congested areas & 36 & 21.7 \\
\hline Stay at home & 11 & 6.63 \\
\hline Keep social distance & 11 & 6.63 \\
\hline Avoid touching face before washing hands & 3 & 1.81 \\
\hline Adhere to government instructions & 21 & 12.7 \\
\hline
\end{tabular}

Source: Field Data, 2020

The results in Table 5 show that the majority of respondents 53(31.9\%) mentioned frequent hand washing as the dominant way; avoiding highly congested areas $36(21.7 \%)$ and the use of sanitizers was mentioned by $21(12.7 \%)$. However, very few respondents $3(1.8 \%)$ 


\section{Macrothink}

Journal of Public Administration and Governance ISSN 2161-7104 2020, Vol. 10, No. 3

mentioned avoiding touching face before washing hands. These results imply that frequent hand washing was a dominant way to show the preparedness of the local community to curb the coronavirus.
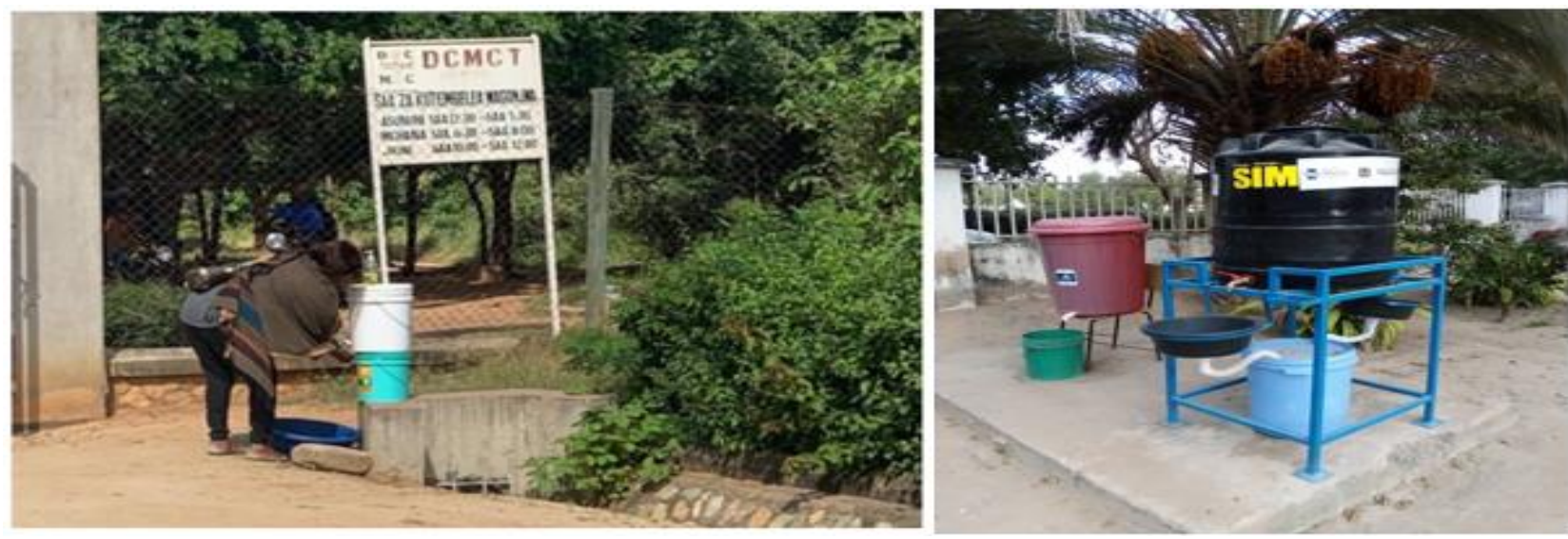

Source: dthd.org/currrent-news/\#.XuymR2gzbIU18/06/2020

Mandatory hand washing stations are placed at the entrances of shops, bars, hospitals, banks, and all public places in Dodoma City to facilitate hand-washing exercises to citizen.

Moreover, the impact of the respondents' level of education on preparedness to curb the disease was assessed to shed more lights. The responses were categorized into three groups including well-prepared, moderately prepared, and poorly prepared. The results regarding respondents' preparedness concerning the education level are summarized in Table 6.

Table 6. Respondents' preparedness level by education

\begin{tabular}{lcccc}
\hline Preparedness & $\begin{array}{c}\text { Bachelor and } \\
\text { above }\end{array}$ & $\begin{array}{c}\text { Education level } \\
\text { Secondary } \\
\text { Education }\end{array}$ & STD VII & Total \\
\hline Well Prepared & 28 & 14 & 9 & 51 \\
Percent & 29.47 & 14.73 & 9.47 & 53.68 \\
Moderate Prepared & 17 & 13 & 12 & 42 \\
Percent & 17.89 & 13.69 & 12.63 & 44.21 \\
Poorly Prepared & 1 & 0 & 1 & 2 \\
Percent & 1.05 & 0 & 1.05 & 2.11 \\
\hline Total & $\mathbf{4 6}$ & $\mathbf{2 7}$ & $\mathbf{2 2}$ & $\mathbf{9 5}$ \\
& $\mathbf{4 8 . 4 2}$ & $\mathbf{2 8 . 4 2}$ & $\mathbf{2 3 . 1 6}$ & $\mathbf{1 0 0}$ \\
\hline
\end{tabular}

Source: Field Data, 2020

Table 6 shows that $29.47 \%$ of the respondents with a minimum of bachelor degrees revealed that they were well prepared to curb the spread of the virus. Likewise, $14.73 \%$ of the respondents with secondary education held similar views. Additionally, $9.47 \%$ of the respondents with primary education level reported similar results. Moreover, $17.89 \%$ of the respondents with a minimum of bachelor were moderately prepared to curb the coronavirus. 


\section{Ml Macrothink}

Journal of Public Administration and Governance

ISSN 2161-7104

2020, Vol. 10, No. 3

However, $2.11 \%$ of respondents were poorly prepared to curb COVID-19. The overall results show that the majority of respondents were well and moderately prepared. Further, results show that the respondents with a minimum of bachelor degrees were well prepared compared to ones with secondary and primary education. This implies that the more the education respondents had, the more they were prepared.

\subsection{Binary Logistic Regression Analysis}

Binary Logistic Regression Analysis was used to assess the influence of age, education level, and sex to local community preparedness. The summary of the regression analysis is provided in Table 7.

Table 7. Analysis of Maximum Likelihood Estimates

\begin{tabular}{|c|c|c|c|c|c|c|c|}
\hline \multicolumn{8}{|c|}{ Analysis of Maximum Likelihood Estimates } \\
\hline Parameter & & $\mathrm{DF}$ & Estimate & $\begin{array}{l}\text { Standard } \\
\text { error }\end{array}$ & $\begin{array}{l}\text { Wald } \\
\text { Chi-Square }\end{array}$ & P-value & $\operatorname{Exp}($ Est $)$ \\
\hline Intercept & & 1 & -0.4274 & 0.7842 & 0.297 & 0.5858 & 0.652 \\
\hline Age & & 1 & 0.0123 & 0.0242 & 0.2584 & 0.6112 & 1.012 \\
\hline \multirow[t]{2}{*}{ Education } & $\begin{array}{l}\text { Bachelor } \\
\text { and above }\end{array}$ & 1 & 0.7475 & 0.4282 & 3.048 & 0.0808 & 2.112 \\
\hline & Secondary & 1 & 0.326 & 0.4911 & 0.5788 & 0.489 & 1.585 \\
\hline Sex & Female & 1 & 0.4161 & 0.2318 & 3.2217 & 0.0727 & 1.516 \\
\hline
\end{tabular}

The analysis showed that the parameter estimate and odds ratio for the variable (age) was 0.0123 and 1.012 respectively implying that, for a year increase in age, a possibility of a respondent to be well-prepared increase by a factor of 1.012 although insignificant. The respondents with at least a bachelor's Degree revealed a higher possibility of preparedness. The level of preparedness increased by a factor of 2.112 compared to STD VII. Parameter and odd for the secondary school were 0.326 and 1.585 respectively, implying that the probability of preparedness level for secondary respondents to be well-prepared increases by a factor of 1.485 compared to STD VII. For variable sex, odds and parameters were 1.516 and 0.4161 respectively for females. It implied that a probability of female respondents to be well prepared increased by a factor of 1.516 compared to male.

\subsection{Prone Areas for COVID-19}

There are different prone areas for the spread of COVID-19 in the study area as mentioned by respondents as indicated in Table 8 .

Table 8. Prone Areas to COVID-19 in Dodoma Urban (N=98)

\begin{tabular}{llcc}
\hline S/N & Areas & f & \% \\
\hline 1. & Markets and Bus Stand & 42 & 44 \\
2. & Recreational centers (Playing grounds, bars, hotels, pubs, and & 20 & 20 \\
& clubs) & & \\
3. & Religious gatherings (Churches and Mosques) & 16 & 16 \\
4. & Workplaces (schools, hospitals, banks) & 11 & 11 \\
5. & Social gathering (Music festivals, wedding, and funnels) & 9 & 9 \\
\hline & Total & $\mathbf{9 8}$ & $\mathbf{1 0 0}$ \\
\hline
\end{tabular}




\section{MlMacrothink}

Journal of Public Administration and Governance

ISSN 2161-7104

2020, Vol. 10, No. 3

Source: Field Data, 2020

Results in Table 5 show the prone areas to the spread of COVID-19, whereas $44 \%$ of the respondents indicated markets and bus stand. Also, $20 \%$ of the respondents indicated recreational centers including playing grounds, bars, hotels, pubs, and clubs, $16 \%$ indicated religious gatherings (churches and mosques), 11\% indicated workplaces, and $9 \%$ indicated social gatherings such as music festivals, wedding, and funnels. The overall results suggest that majority of the respondents had the feeling that markets, bus stands, and recreational centers are the most prone areas to the spread of COVID-19. The results imply that preventive measures should be intensively imposed in those areas to mitigate the spread of coronavirus.

\subsection{Suggested Measures to Overcome the Spread of COVID-19 in the Prone Areas}

Respondents suggested measures to mitigate the spread of COVID-19 in the most exposed areas. The summary of the suggested measures is presented in table 9.

Table 9. Suggested Measures to overcome the spread of COVID-19 in prone areas (N=92)

Suggestion

Number suggested Percentage

Rapid screening and testing to make sure all citizens in the community are safe.

Establish Isolation areas to take care confirmed cases

Impose social distancing practices in churches, mosques, markets and bus stands and recreational centers

Restrict unnecessary movements especially in public places

Use local leaders in the campaign against COVID-19

Provision of masks, sanitizers and health services to the need citizens

Provide instructional and preventive guidelines to all citizens

Source: Field Data, 2020

The findings in Table 8 indicated a number of the suggested measures to minimize the spread of the disease. Among them, the measures which were given due attention include, improvement in social distancing in religious institutions, market places and bus stand (47\%), restricting movements in public places (39\%), provision of masks, sanitizers and health services to the needy people (29\%), Provide instructional and preventive guidelines to all citizens $(27 \%)$ and rapid screening and testing at community grassroots level (24\%). 


\section{MInstitute ${ }^{\text {Mink }}$}
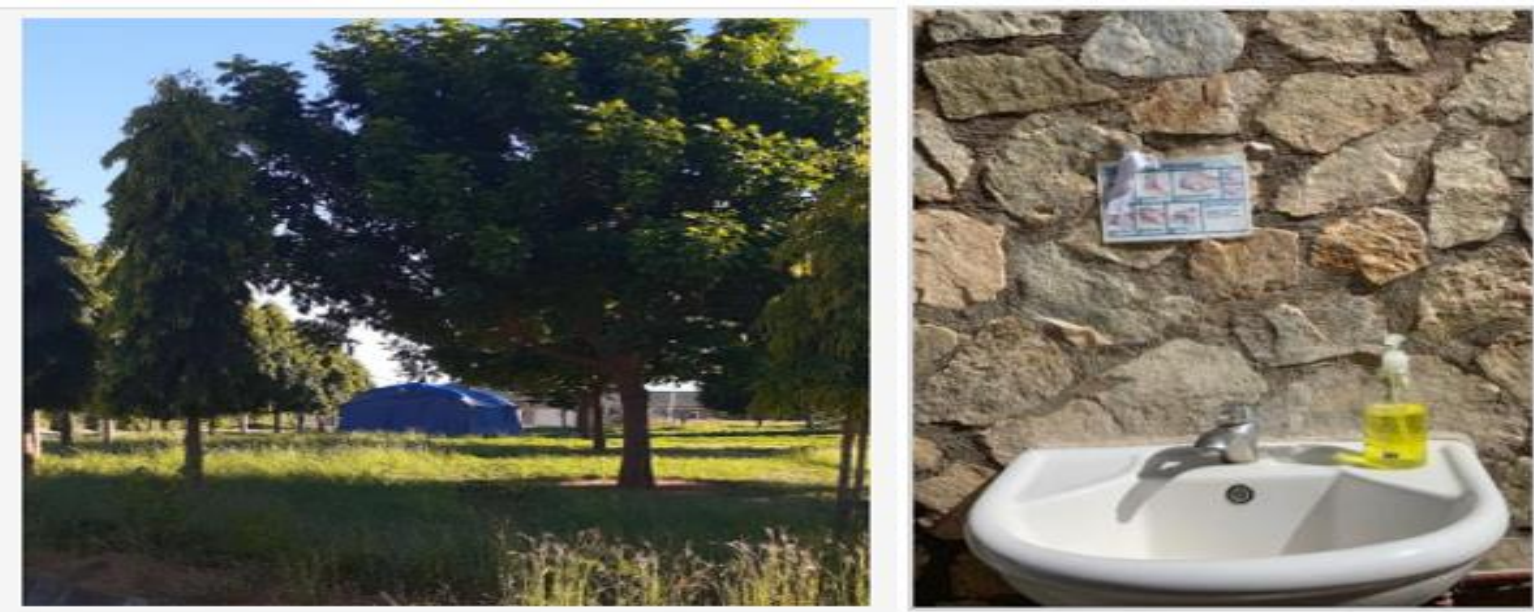

An isolation tent from The Red Cross set up outside of the Dodoma Cristian Medical Centre (DCMC). Any patient suspected of the virus will be moved to this tent, and later all will be transferred to larger isolation units in Mkonze, Dodoma. Also information regarding methods to stop the spread of the virus is posted throughout the public places

Source: dthd.org/currrent-news/\#.XuymR2gzbIU18/06/2020

The findings imply that when these measures are effectively undertaken, the spread of the disease in the prone areas will be checked. The findings imply that social distancing during the conduct of religious activities is perceived as an important measure to minimize the spread of the virus, followed by restrict movements in public places such as bus stand and markets.

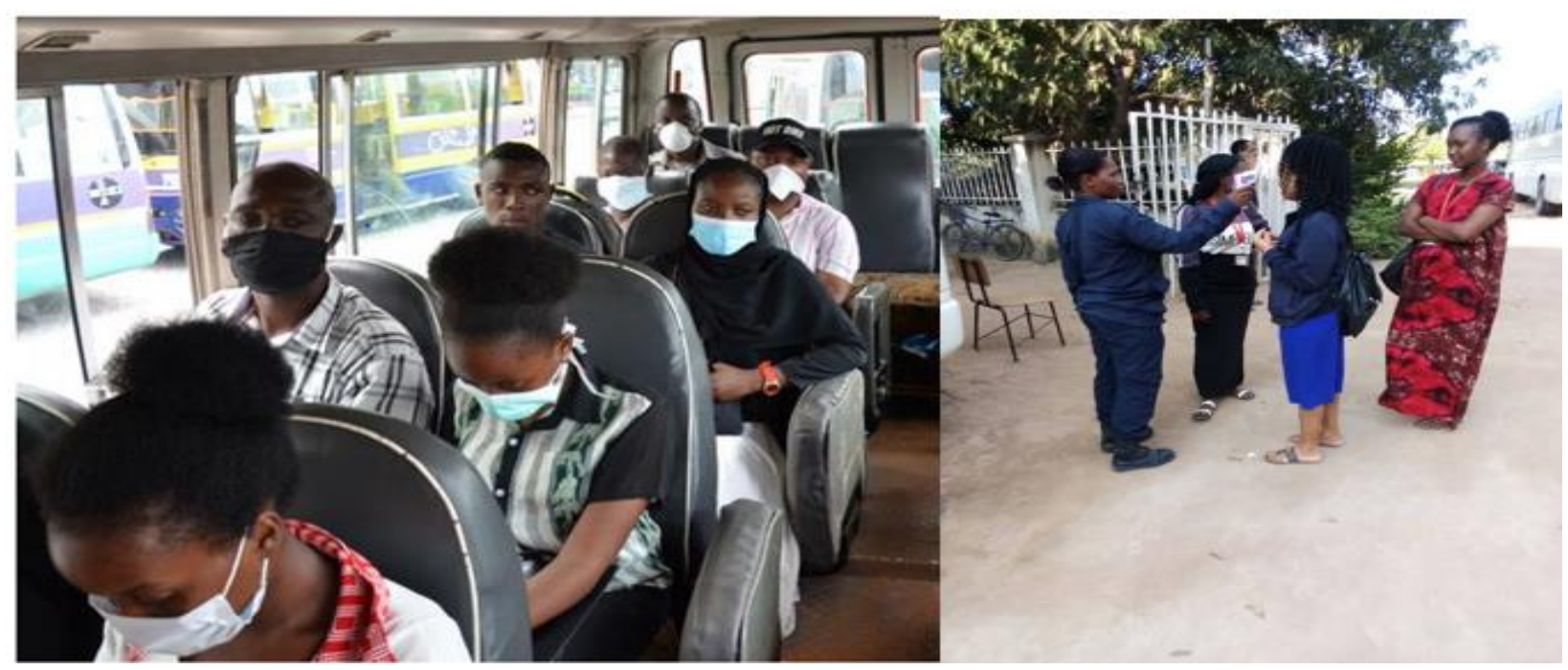

Wearing masks and body temperature testing has been the practice and mandatory in public places in Dodoma urban including government offices, supermarkets, banks and hospitals.

\section{Discussion}

Our goal in this study was to examine the preparedness of the local community in the fight against COVID-19. The study has presented the results on the aspects of community 
awareness on the disease, the ways through which COVID-19 spread, and the community preparedness to fight against the pandemic. Also, areas that are prone to the spread of COVID-19; and the ways of improving community adherence to government directives on the spread and prevention of the disease.

Generally, although in varying extents, all the respondents revealed a certain level of awareness about COVID-19 and its spread mechanisms. The level of awareness among the respondents is categorized into high, moderate, and poor understanding. Of all the respondents, only 16 had a high understanding, 48 of them had moderate understanding and 31 of the respondents revealed poor understanding regarding the disease and its spread mechanisms. Similar results were presented by (Survey et al., 2020) who conducted a cross-sectional survey to determine COVID-19 awareness, knowledge, attitudes, and related behaviors among the U.S to 630 respondents. They found that $100 \%$ of the respondents had heard of the coronavirus (COVID-19), and most considered the potential threat to be high. Roy et al. (2020) in their study of knowledge, attitude, anxiety \& perceived mental healthcare need in the Indian population during the COVID-19 pandemic, found that respondents had a moderate level of knowledge about the COVID-19 and adequate knowledge about its preventive aspects. Moreover, (Clin et al., 2020) conducted an assessment study of Iranian Nurses' Knowledge and Anxiety toward COVID-19 during the Current Outbreak in Iran, found that the awareness of more than half of (56.5\%) Iranian nurses had good knowledge regarding COVID-19. This study found dissimilar results from the current findings. Adding to the previous studies, the findings of this study recommends to enhance information sharing about the disease in order improve the understanding among the respondents with moderate and low understanding about the disease. The improved understanding is among the perquisite requirements for laying measures to mitigate the spread of the disease and its impacts on the respective community.

Likewise, respondents revealed their understanding regarding the ways through which the COVID-19 can spreads. The ways included touching the droplets or fluid from a victim after sneezing (42.2\%), coughing, and handshake (39.4\%), direct contact with the COVID-19 patient $(23 \%)$, through the air $(20.2 \%)$, and touching contaminated surfaces $(16.2 \%)$. The awareness on the ways through which the virus gets into people is a paramount factor in mitigating its spread. The community members being aware of ways in which the disease can spread, it becomes easy to design effective mechanism to avoid the prone areas and put in place redresal mechanisms. The findings relate with the observations by Singhal (2020), Spina et al. (2020), Qin et al., (2020), WHO, 2020) Wang \& Du, (2020) who establishe inter alia touching large droplets generated by symptomatic patients through sneezing, coughing, and handshaking, inhaling droplets generated when the affected person coughs or sneezes or touches a surface where these droplets land and then touching one's face or nose are the main routes of transmission of COVID-19. Having the perquisite level of understanding regarding the ways through which the disease spreads cannot only make the waging the war against the virus easy in the country but also mitigate its spread globally. It has to be crystal clear that COVID-19 is a borderless virus.

Moreover, apart from awareness level of the respondents on COVID-19 and the ways through 
which COVID-19, the respondents revealed a number of the ways to mitigate the spread of the disease. They include washing hands by clean running water and soap 53(31.9\%), avoiding highly congested areas 36(21.7\%), and use of sanitizers 21(12.7\%). The employees' awareness on the disease, the ways through which it spreads and the mechanisms to mitigate its spread, it is an indicator that waging the war against it is possible. The respondents' awareness in in the diverse aspects of the COVID-19 is an indicator that substantial efforts were undertaken to sensitize community on the disease. The efforts in place promise that further efforts to address the spread of the disease are possible. Likewise, the efforts are likely to bear the fruits when taken in relation with other measures. The measures include closing recreational places e.g. pubs and clubs, partial lockdown in the affected regions, introduce social distancing in churches, and mosques. These indeed are mild containment and mitigation measures to limit the spread of the disease and serve lives. However, its implementation is associated with some costs. The costs include inter-alia detrimental effects on the economic activities which restraining and the flow of goods and services from and outside Tanzania. This in turn is likely to have social and economic impacts on the lives of the citizens and the lives of other people in the nearby countries.

\section{Conclusion}

Since its outbreak in late December 2019, COVID-19 has brought a state of fear, panic, insecurity and a high level of uncertainty to the whole population of the world. Amid these uncertainties, governments and international organizations across all continents, have adopted various measures to counter the spread of the disease. Such measures have depended on the nature and severity of the disease and suitable approaches adopted by each country. This study has highlighted several issues regarding the preparedness of the Dodoma urban local community in the fight against COVID-19. Also, several ways as to how the community is prepared including the use of sanitizers, washing hands, wear masks and social distancing approaches, stay at home, etc. have been provided. However, the Tanzania government needs to weigh carefully the effectiveness of each containment and mitigation measures to avoid unintended social and economic consequences. It should therefore, adopt measures concomitant to its capacity in terms of social, political, and economic characteristics. Further, in this situation, leadership preparedness including providing hopes and reducing fear and anxiety among citizens as the leadership of the President of Tanzania Honourable Dr. John Pombe Joseph Magufuli has regularly provided is pertinent. While evidence shows that community is somehow prepared to curb the spread of the disease, we recommend continued efforts to enhance local community adherence to the government directives to address the pandemic. This is possible when the community is constantly informed of the pandemic situation, as it may help them to protect their families, and others against COVID-19. Finally, corroborative efforts between the government, civic organizations, international organizations, religious leaders, and citizens in the fight against the coronavirus pandemic are crucial.

\section{References}

Acharya, R., Gundi, M., Ngo, T. D., Pandey, N., Patel, S. K., Pinchoff, J., ... Zavier, A. J. F. (2020). COVID-19-related knowledge, attitudes, and practices among adolescents and young 
people in Bihar and Uttar Pradesh, India: Study description, 1-6.

Austrian, K., \& Abuya, T. (2020). NAIROBI INFORMAL SETTLEMENTS : COVID-19.

Benvenuto, D., Angeletti, S., Giovanetti, M., Ciccozzi, A., Spoto, S., \& Ciccozzi, M. (2020). The 2019 - new coronavirus epidemic: Evidence for virus evolution, (January), 455-459. https://doi.org/10.1002/jmv.25688

Clin, A., Dis, I., Press, I., Press, I., Nemati, M., Ebrahimi, B., \& Nemati, F. (2020). Assessment of Iranian Nurses ' Knowledge and Anxiety Toward COVID-19 During the Current Outbreak in Iran Assessment of Iranian Nurses' Knowledge and Anxiety Toward COVID-19 During the Current Outbreak in Iran, (March). https://doi.org/10.5812/archcid.102848

Dosa, D., Jump, R. L. P., D, K. L. P., \& Gravenstein, S. (2020). Long-Term Care Facilities and the Coronavirus Epidemic: Practical Guidelines for a Population at Highest Risk. Journal of the American Medical Directors Association, 121, 10-12. https://doi.org/10.1016/j.jamda.2020.03.004

Korea, S., \& Kong, H. (2020). How will country-based mitigation measures influence the course of the COVID-19 epidemic?, 2019(20), 931-934. https://doi.org/10.1016/S0140-6736(20)30567-5

Level, R., Level, G., High, V., High, V., \& High, V. (2020). Coronavirus disease 2019 ( COVID-19 ), 2019(March).

Lippi, G., \& Plebani, M. (2020). Letter to the Editor Laboratory abnormalities in patients with COVID-2019 infection.

Loayza, N. V, \& Pennings, S. (2020). Research \& Policy Briefs Macroeconomic Policy in the Time of COVID-19 : A Primer for Developing Countries, (28).

Purcell, L. N., \& Charles, A. G. (2020). An Invited Commentary on "World Health Organization declares global emergency: A review of the 2019 novel Coronavirus ( COVID-19 )": Emergency or new reality? International Journal of Surgery, 76(March), 111. https://doi.org/10.1016/j.ijsu.2020.03.002

Qian, X., Ren, R., Wang, Y., Guo, Y., Fang, J., Wu, Z., ... Han, T. (2020). Fighting against the common enemy of COVID-19: a practice of building a community with a shared future for mankind, 4-9.

Qin, Q., Wang, Y., Wang, Y., Chen, Y., Qin, Q., Province, G., \& Hospital, U. (2020). Unique epidemiological and clinical features of the emerging 2019 novel coronavirus pneumonia (COVID-19) implicate special control measures, 0-1. https://doi.org/10.1002/jmv.25748

Roy, D., Tripathy, S., Kar, S. K., Sharma, N., Verma, S. K., \& Kaushal, V. (2020). Jo ur na 1 P re of. Asian Journal of Psychiatry, 102083. https://doi.org/10.1016/j.ajp.2020.102083

Singhal, T. (2020). A Review of Coronavirus Disease-2019 (COVID-19), 87(April), 281-286. 


\section{Macrothink}

Spina, S., Marrazzo, F., Migliari, M., Stucchi, R., Sforza, A., \& Fumagalli, R. (2020). Correspondence The response of Milan's Emergency Medical System to the COVID-19 outbreak in Italy. The Lancet, 395(10227), e49-e50. https://doi.org/10.1016/S0140-6736(20)30493-1

Survey, A. C., Wolf, M. S., Serper, M., Opsasnick, L., Conor, R. M. O., \& Curtis, L. M. (2020). O RIGINAL R ESEARCH Awareness , Attitudes , and Actions Related to COVID-19 Among Adults With Chronic Conditions at the Onset of the U. S . Outbreak. https://doi.org/10.7326/M20-1239

Talukder, A. K., Sheikh, B., Rahman, M., Sheikh, B., Rahman, M., Engineering, G., ... Rahman, M. (2020). Tackling the Pandemic COVID-19: the Bangladesh Perspective, (April), 1-18. https://doi.org/10.20944/preprints202004.0384.v1

Wang, J., \& Du, G. (2020). COVID-19 may transmit through aerosol, (5), 5-6.

Williams, V. (2020). COVID-2019 - LESSONS TO LEARN IN AFRICA ( SHORT COMMUNICATION ) A CRITICAL REVIEW ON THE POTENTIAL EFFECT OF COVID-2019 ON AFRICA AND LESSONS TO BE LEARNT, 19, 49-51.

\section{Copyright Disclaimer}

Copyright for this article is retained by the author(s), with first publication rights granted to the journal.

This is an open-access article distributed under the terms and conditions of the Creative Commons Attribution license (http://creativecommons.org/licenses/by/4.0/). 